\title{
The Treadmill of Alternatively Fueled Vehicle Production
}

\author{
Julius McGee' \\ Department of Sociology \\ Portland State University, Oregon, United States
}

\section{Abstract}

This paper examines the extent to which alternatively fueled vehicles (AFVs) act as a counterforce to traditional fuel consumption in the United States. I estimate a time-series cross-sectional Prais-Winsten regression model with panel-corrected standard errors to explore how increases in the proportion of AFVs influences fuel consumption rates per vehicle. Findings indicate that AFVs are increasing the average fuel consumption rates of vehicles. Using an additional time-series cross-sectional Prais-Winsten regression model with panel-corrected standard errors, I demonstrate that at least part of this correlation is due to AFVs' positive relationship to travel. I explain this phenomenon using the treadmill of production theory (a prominent theory in environmental sociology), and argue that AFVs up until this point have been used to expand development, and in turn environmental impacts. Furthermore, I argue that the inability of AFVs to replace traditional fuel consumption demonstrates a paradox in their application that can be explained through the treadmill of production theory.

Keywords: alternatively fueled vehicles, ecological paradoxes, fuel consumption, treadmill of production

\section{Introduction}

It is often assumed by nations and international organizations that alternative resources directly substitute their fossil-fueled-based counterparts (National Renewable Energy Laboratory, 2013; UNEP, 2011). Whether or not this is the case has been a key concern for social scientists, as it is often noted due to the many complexities embedded within modern socioeconomic processes that new resources aimed at substituting conventional goods do not result in their expected outcome (McGee, 2015; York, 2006). For example, York (2012) found that alternative forms of energy have an unexpected impact on fossil fuel sources of energy. Specifically,

$1 \quad$ Author contact: cjulius@pdx.edu 
he noted that while the expectation is that one unit of alternative energy displaces a proportional unit of fossil fuel, in actuality, alternative sources of energy only minutely displace fossil fuel sources. Outcomes such as these have been referred to as "paradoxes" (McGee 2015; York 2006), and can be explained using prominent theories in environmental sociology (see Foster, 1999, 2000; Schnaiberg, 1980; York, 2004).

One such theory, which I will be using in this analysis, is treadmill of production theory (ToP), which was developed by Allan Schnaiberg (1980) to explain the socioeconomic processes that drive ecological destruction. ToP is often employed as a theoretical explanation for empirical evidence of increased anthropogenic environmental degradation (see Besek \& McGee, 2014; Clausen \& York, 2008; Clement \& Schultz, 2011; Jorgenson \& Clark, 2012; York et al., 2003). Additionally, it is commonly juxtaposed against another prominent theory in environmental sociology: ecological modernization theory (EMT) (Mol et al., 2009), where researchers assess whether various socioeconomic processes are leading to further environmental harm (explained by ToP) or environmental reform (explained through EMT). A strong correlation between socioeconomic development and increased environmental degradation is often seen as evidence of ToP, while the opposite is argued to be evidence of EMT. However, as EMT and ToP theorists have noted, the empirical goal of EMT is to analyze specific instances of environmental reform, and not necessarily the broader connection between socioeconomic development and ecological processes (Mol et al., 2014; York, 2004; York \& Rosa, 2003). As a result, many debates between EMT and ToP have focused on different processes and levels of socioeconomic development. The present study seeks to apply a different approach to this long-standing debate by exploring a specific instance of environmental reform and assessing its ability to counteract environmentally hazardous processes. Specifically, here I ask if there is a paradox in the production of alternatively fueled vehicles (AFVs) in the United States.

I estimate time-series cross-sectional Prais-Winsten regression models with panelcorrected standard errors to explore (1) how increases in the percentage of AFVs across the United States from 2003 to 2014 affect the fuel consumption rates of all vehicles and (2) how increases in the proportion of AFVs affect the travel rates of vehicles. In the first model, I find that a one-unit increase in the proportion of AFVs increases the rate of fuel consumption per vehicle. In the second model, I find that increasing the proportion of AFVs is correlated with increased miles traveled per vehicle, which offers insight into my first finding. I contextualize this phenomenon using ToP, and argue that this instance of environmental reform does not counteract the treadmill of production. I juxtapose this finding against EMT in a slightly more nuanced way than traditional studies exploring these theories (Besek \& McGee, 2014; Clausen \& York, 2008; York et al., 2003) by empirically examining a specific instance of environmental reform and contextualizing it as a facet of ToP. 


\section{Previous discussions on alternatively fueled vehicles}

Previous studies of AFVs have predominantly focused on two phenomena-the integration of AFVs into the larger vehicle fleet and the environmental consequences of AFVs. A common thread between these types of analyses is the ability of AFVs to act as a counterforce to climate change and other environmental impacts deriving from gasoline- and diesel-based vehicles. For example, Tran et al. (2013) quantify the conditions that may trigger widespread adoption of AFVs, and identified the barriers that exist for early and mass adoption of AFVs. The authors note that for early adoption, a major barrier, particularly for battery-electric vehicles, is price premiums and the lack of available charging facilities. They find that the integration of AFVs is largely dependent upon a vehicle market that values carbon reduction, which they note is currently not the main motivation behind early adopters, as most consumers are influenced by the financial rather than environmental benefits of AFVs. In a similar vein, Zhang et al. (2011) explore factors that could "speed the diffusion of AFVs," finding that market pull factors such as "word-of-mouth" have a positive impact on the potential diffusion of AFVs. However, the authors also find that government mandates on fuel economy standards aimed at reducing carbon emissions decreases the diffusion of AFVs due to increases in the market share of fuel-efficient vehicles. Egbue and Long (2012) argue that an additional hurdle to the widespread distribution of electric vehicles is consumers' hesitancy to adopt "unproven" technology. They contend that this hurdle limits the effectiveness of AFVs to reduce greenhouse gas emissions from "conventional vehicles."

In studies emphasizing the environmental consequences of AFVs, scholars similarly focus on the ability of AFVs to reduce environmental degradation and compare the merits of AFVs to traditional vehicles. For example, Moriarty (1994) assessed the extent to which electric cars reduced greenhouse gas emissions in Australia, finding that if the electric grid could be made up of at least 15\% wind energy, replacing traditionally fueled vehicles with electric cars would reduce greenhouse gas emissions relative to their petroleum-based counterparts. Additionally, Moriarty argued that ethanol from sugar cane had high costs per ton of $\mathrm{CO}_{2}$ reduction and, when other trace gases were considered, showed no definite improvement over petroleum.

More recently, Lapola et al. (2010) found that carbon emissions derived from land-use change perpetuated by the growing demand for biofuels in Brazil would be low due to their replacement of rangeland. However, Lapola also argues that indirect land-use changes, especially those pushing the rangeland frontier into the Amazonian forests, could offset the carbon savings from biofuels, illustrating that growth in biofuel production can potentially yield little to no reduction in overall environmental degradation. 
Other studies have used life cycle analysis to explore the varying environmental impacts of AFVs (e.g., Hill et al., 2006; Segal, 1995). For example, Ogden et al. (2004) performed a life cycle analysis of numerous categories of AFVs to assess the impacts of each fuel type, and found that hydrogen-based fuel had the lowest externality cost of all types of fuel. This was cited as a result of the life cycle cost of hydrogen-based vehicles as compared to newer gasoline-based vehicles, which does not include the cost of extraction. Other research has also found there may be additional individual health risks associated with AFVs. Specifically, Lapin et al. (2002) found that currently employed natural gas-fueled heavy-duty trucks have particulate exhaust emissions that engender mutagenic activity, which is known to cause serious human health risks.

It is clear based on these analyses that scholars are particularly interested in the ability of AFVs to replace traditional vehicles and reduce environmental degradation. Theoretically, these concerns and findings align with notions in ToP and EMT. A frequent debate among EMT and ToP theorists is the ability of existing political economic structures to incorporate meaningful environmental reform. The studies noted above acknowledge the potential environmental benefits of AFVs, as well as the socioeconomic barriers preventing their further application. The debate among ToP and EMT places these concerns in a broader theoretical context that provides new insights into the application of AFVs. Below I discuss the ToP/EMT literature in an effort to expand on the empirical approaches previously used in this debate.

\section{The paperless office paradox: Treadmill of production versus ecological modernization theory}

ToP argues that the inherent tendency of modern economies is to expand development by increasing resource extraction, which in turn increases environmental impacts (Gould et al., 2008; Schnaiberg, 1980; Schnaiberg et al., 2002). ToP was first developed by Allan Schnaiberg (1980) as a response to the massive increases in resource extraction and environmental destruction that occurred post-World War II. In assessing modern society's relationship to nature, Schnaiberg concluded that environmental degradation is intrinsic to capitalist society such that social inequalities are interwoven with each environmental concern, and that social and political responses to these production processes are ultimately futile and unpredictable (Schnaiberg et al., 2002). Furthermore, the environmentally destructive characteristics of capitalist production are unhindered by consumer and regulatory action aimed at reducing environmental impacts, as these attempts are contingent upon capital investments (Schnaiberg, 1980; Schnaiberg \& Gould, 1994; Schnaiberg et al., 2002). 
Gould et al. (2004) note that each round of investment in capitalist markets consistently increases levels of demand for natural resources for a given level of social welfare. Further, Gould et al. (2004) argue that such investments work to weaken employment circumstances for production workers and degrade the environment. This process is made successful by creating a consistent need for investments to employ workers, and continually extracting a variety of natural resources to produce new goods. ToP theorists argue that this level of dependency on capital reduces consumers' and politicians' ability to work in their best environmental interest (Schnaiberg, 1980). For example, strong environmental regulations from the political sphere are seen as antagonistic to workers, and therefore voters, as regulation can reduce the expansion of jobs by decreasing levels of extraction. This hinders politicians' ability to take regulatory action against environmental degradation.

Workers' and consumers' ability to reduce environmental impacts is weakened by their lack of influence in the fields of resource extraction and production. For instance, if a consumer refrains from participating in an environmentally hazardous market, and there are no environmentally sustainable alternative commodities within said market, they risk acquiring additional socioeconomic burdens that using that commodity may relieve. Additionally, due to the monopolistic nature of modern capitalist economies (see Baran \& Sweezy, 1966), purchasing sustainable alternatives to environmentally hazardous goods often means purchasing products produced by the same companies. This widespread pattern of centralization makes the reduction of environmental impacts contingent upon producers' reallocation of profits. If, for example, a consumer purchases a sustainable product from a company that reinvests its profits into environmentally hazardous production, the overall benefit of such a choice may be reduced or inverted.

In opposition to ToP, EMT suggests that modern economies cannot only respond to escalating environmental catastrophe, but are also best equipped to deal with environmental problems (Mol et al., 2009). EMT often focuses on specific instances of environmental reform (Sarkis \& Cordeiro, 2012; Wattanapinyo \& Mol, 2013; Zhu et al., 2012), contending that the escalating presence of environmental policies and adoption of "green" techniques by businesses are signs of modern economies responding to environmental pressures. In response to these claims, ToP scholars have emphasized abstract socioeconomic processes that demonstrate consistent rises in environmental destruction (Besek \& McGee, 2014; Clausen \& York, 2008; York et al., 2003). For instance, York and Rosa (2003, p. 282) argue that EMT has failed to "explicate the theoretical expectation connecting emergent institutions of modernity with genuine environmental reform," that "case studies, clearly appropriate for in-depth understanding, must be representative of the general process being theorized if they are to validate theory," and that "a focus on individual organizations or industries cannot address critiques of EMT from political economy because the latter theories address economy-wide processes rather than processes 
specific to any single sector or actor within an economy." In responses to these criticisms, EMT contends that these critiques are overtly deterministic and do not recognize the changing landscape of modern economies (Fisher \& Freudenburg, 2001; Mol et al., 2009; Mol et al., 2014). Mol et al. (2014), in their most recent response to neo-Marxist criticisms of EMT, such as York and Rosa’s (2003), argue that these critiques have helped to refine EMT, claiming that "more environmentally friendly and sustainable sociotechnical systems, institutions, policy arrangements and social relations are not only of key academic importance in themselves, but are central also to the identification and understanding of structural, anthropogenic drivers of environmental decay" (Mol et al., 2014, p. 12). These claims of Mol and colleagues suggest that in order to better comprehend environmental degradation, researchers must better understand environmental reform.

York (2004) demonstrates this point in an additional criticism of EMT, arguing that introducing sustainable alternatives to environmentally hazardous markets is simply a "treadmill of diversifying production," where manufacture of "sustainable" products is used to expand markets by meeting diversified consumer interests. This process renders ecologically sustainable resources more a reaction to unsustainable processes, rather than a counterforce, making the increasing prevalence of "ecologically conscious goods" within modern economies an expansion of overall production. In a more recent article, York (2006) further explores this phenomenon, along with the more widely known Jevons paradox (Clark \& Foster, 2001), to question whether technological advances alone lead to conservation of natural resources. Here he contends that in addition to the Jevons paradox, which is a phenomenon where improved resource efficiency escalates the consumption of that resource, there is a paradox of substitution, where new resources fail to reduce existing ones. York calls this paradox the "paperless office paradox," in reference to Sellen and Harper's book The Myth of the Paperless Office (2003).

York (2012) empirically tests this paradox by exploring the extent to which alternative sources of energy displace fossil fuel sources of energy. He finds that the increased presence of alternative sources of energy, such as hydroelectric and nuclear, only minutely displace the production of fossil fuel energy sources, and argues that this goes against traditional assumptions regarding energy expansion. Based on his findings, York concludes that the shift away from fossil fuel energy use does not inevitably occur with the expansion of alternative sources.

McGee (2015) also hypothesizes there is a "paradox" within sustainable markets, finding that organic farming is increasing the emissions of greenhouse gases. McGee concludes that in attempting to expand the use of organic goods, agribusiness in the United States has watered down organic standards in such a way that organic farming no longer needs to rely on practices associated with climate change mitigation. As a result, the increase in organic farming produces a paradox, where organic expansion does not counteract the environmental impacts it is traditionally assumed to. 
York's (2012) and McGee's (2015) findings regarding the paperless office paradox can comprehensively be understood as instances where novel technologies fail to produce their intended outcomes. Their empirical approaches are similar to those used by EMT, as they emphasize perceived instances of environmental reform; however, they contextualize their findings more in line with ToP. These approaches are new ways of exploring the long-standing debate between ToP and EMT regarding the effectiveness of environmental reform. As noted previously, the current literature on the production of AFVs has similarly emphasized the ability of AFVs to substitute traditional vehicles and promote environmental reform. To this end, the hypothesis developed below will place the relationship between AFVs and traditional vehicles within the context of the EMT and ToP debate, with the intention of elaborating on the structural barriers preventing further application of AFVs.

\section{Hypothesis}

I ask whether increasing the proportion of AFVs within the vehicle fleet increases or decreases total fuel consumption rates per vehicle. This question is articulated in the hypotheses below.

H1: Increasing the proportion of $A F V$ s within the vehicle fleet reduces the total amount of fuel consumed by vehicles in the United States.

H2: Increasing the proportion of AFVs within the vehicle fleet increases the total amount of fuel consumed by vehicles in the United States.

$\mathrm{H} 1$ assumes that $\mathrm{AFV}$ s are operating as a counterforce to the treadmill of production and as a process of ecological modernization by reducing the amount of fuel that is consumed by vehicles annually at the state level. This outcome could be a result of multiple factors, such as AFVs having higher fuel efficiency or AFVs being associated with lower rates of travel. Additionally, this hypothesis assumes that AFVs are displacing traditional vehicles. In contrast to $\mathrm{H} 1, \mathrm{H} 2$ assumes that AFVs are acting as a facet of the treadmill of production and increasing the amount of fuel consumed by vehicles at the state level. Similarly, to $\mathrm{H} 1, \mathrm{H} 2$ could be a result of multiple factors, such as lower fuel efficiency among AFVs, the number of AFVs adding to the total number of vehicles in the vehicle fleet, or AFVs increasing travel.

To further understand the extent to which AFVs act as a facet of the treadmill of production or a form of ecological modernization, I pose the additional question of whether rises in the proportion of AFVs increase or decrease the number of miles traveled by vehicles at the state level. This question is articulated in the following hypotheses: 
H3: Increasing the proportion of AFVs within the vehicle fleet decreases the number of miles traveled per vehicle in the United States.

H4: Increasing the proportion of AFVs within the vehicle fleet increases the number of miles traveled per vehicle in the United States.

$\mathrm{H} 3$ assumes that one way AFVs operate as a counterforce to the treadmill of production is by reducing the number of miles traveled by vehicles at the state level. Conversely, $\mathrm{H} 4$ assumes that one of the ways in which AFVs act as a facet of the treadmill of production is by increasing the number of miles traveled by vehicles at the state level. Although $\mathrm{H} 1$ and $\mathrm{H} 3$ both assume that AFVs operate as a counterforce to the treadmill of production, $\mathrm{H} 1$ can be confirmed while $\mathrm{H} 3$ is rejected and vice versa. For example, it may be the case that AFVs are on average more fuel efficient than gasoline and diesel vehicles, consuming less fuel per vehicle, but that travel is increased due to the increased fuel efficiency. This argument is similar to the rebound effect (see Greening et al., 2000; Small \& Van Dender, 2005, 2007; Sorrell, 2007), which argues that consumption rates for gasoline grow due to lower cost from increased fuel efficiency and behavioral shifts in consumers. Likewise, $\mathrm{H} 1$ can be rejected while $\mathrm{H} 3$ is confirmed if AFVs act as a facet of the treadmill of production by increasing fuel consumption per vehicle due to lower fuel efficiency rates, but reduce the average amount of travel per vehicle as a result of minimal infrastructure for AFVs.

\section{Data and methods}

In order to test my hypotheses, I estimated three elasticity models (shown in Tables 3 and 4), which were created by taking the natural log of my dependent and independent variables. Elasticity models assume that a dependent variable is determined by a multiplicative combination of the independent variables. Multiplicative models intrinsically take into account one type of interaction among factors by recognizing that a change in one independent variable does not simply add to the dependent variable directly, but rather scales it relative to the values of the other factors. Additionally, each coefficient for my independent variables is interpreted as the proportional effect of a $1 \%$ change of the independent variable on the dependent variable.

Each model is estimated using a time-series cross-sectional Prais-Winsten regression model with panel-corrected standard errors (PCSE), allowing for disturbances that are heteroskedastic and contemporaneously correlated across panels (see Beck \& Katz, 1995). Each model estimates the relationship from 2003 to 2014 across the United States (excluding the District of Colombia). I include state-specific and year-specific intercepts, meaning the fixed effects of this model are both unit and time specific. As such, this method estimates effects within states, rather than 
between states, over time and controls for variation between states. Finally, I correct for autoregressive (AR1) disturbances within panels, treating the $\mathrm{AR}(1)$ process as common to all panels because there is no theoretical reason to assume the process is panel specific (see Beck \& Katz, 1995). The model I estimate is:

$\mathrm{y}_{\mathrm{it}}=\mathrm{B}_{1}\left(\mathrm{x}_{1 \mathrm{it}}\right)+\mathrm{B}_{2}\left(\mathrm{x}_{2 \mathrm{it}}\right) \ldots \mathrm{B}_{\mathrm{k}}\left(\mathrm{x}_{\mathrm{kit}}\right)+\mathrm{u}_{\mathrm{i}}+\mathrm{w}_{\mathrm{t}}+\mathrm{e}_{\mathrm{it}}$

Here the subscript ${ }_{i}$ represents each unit of analysis (states) and the subscript the time period, $y_{i t}$ is the dependent variable for each state at each point in time, $\mathrm{x}_{\mathrm{kir}}$ represents the independent variables for each state at each point in time, $\mathrm{u}_{\mathrm{i}}$ is a state-specific disturbance term that is constant over time (i.e., the state-specific $\mathrm{y}$-intercept), $\mathrm{w}_{\mathrm{t}}$ is a period-specific disturbance term constant across states, and $\mathrm{e}_{\mathrm{it}}$ is the stochastic disturbance term specific to each state at each time point.

The logic of my modeling approach is to observe how change in the number of AFVs effects change in the dependent variables. I chose to use a PCSE model with year- and state-specific intercepts because it allows me to specifically assess the effect of change from year to year within states as opposed to differences across states.

\section{Dependent variables}

The data for the dependent variables were obtained from the United States Office of Highway Policy Information (OHPI). ${ }^{2}$ The data include annual motor fuel consumption rates for all civilian vehicles and the total number of vehicles. The data on motor fuel consist of gasoline, gasohol, diesel, ethanol ( $85 \%$ or higher), compressed natural gas, electricity, hydrogen, liquefied natural gas, and liquefied petroleum all measured in gasoline-equivalent gallons. The data for motor fuel consumption are estimated based on motor fuel sellers' federal and state tax returns. Specifically, OHPI (2015, pp. 2-11) states:

The major component of the gross volume is the tax returns of sellers (depending on the point of taxation in the State, the sellers are: position holders at fuel terminals, wholesalers, or retailers). Include the gross motor fuel sales reported by these taxpayers, including fully taxed sales, exempt sales, volume subject to full or partial refund, and sales taxed at a reduced rate. Include gasoline volume subject to exemption due to actual loss or subject to loss or shrinkage allowance.

2 Office of Highway Policy Information, 2014, retrieved from www.fhwa.dot.gov/policyinformation/ statistics.cfm, 2016. 
It is also important to note that this methodology potentially underestimates the fuel consumption of electric vehicles, since a portion of electric fuel consumption derives from private residences. However, based on the findings discussed below, inclusion of these data would most likely further support the results of this analysis, as it suggests that the total amount of fuel consumption is underestimated.

The first dependent variable (Table 1) was calculated by dividing the total amount of fuel consumed by civilian vehicles by the total number of civilian vehicles, which includes all mid-sized automobiles, compact automobiles, full-size automobiles, subcompact automobiles, low-speed vehicles, motorcycles, sport-utility vehicles (SUVs), pickup trucks, full-size trucks, light-weight vans, mid-size vans, and mini vans.

The second dependent variable (Table 1) was also obtained from OHPI and measures the total number of miles traveled per vehicle. This variable was created by dividing the total number of miles traveled by the total number of vehicles. The data for motor fuel consumption, total number of vehicles, and miles traveled per vehicle rely on annual state reports, where each state follows established federal guidelines to maintain consistency across regions. The OHPI notes "these estimates may not be comparable to data for prior years due to revised estimation procedures." However, the most recent revised estimation procedure occurred in 2002 when an automated data submittal process was implemented by a web-based application, which was intended to ease the reporting burden and improve data accuracy. Thus the data used in this analysis are not subject to this particular inaccuracy.

Table 1. Summary statistics of dependent variables (unlogged)

\begin{tabular}{|l|c|c|c|c|}
\hline Variable & Mean & Minimum & Maximum & $\begin{array}{c}\text { Standard } \\
\text { deviation }\end{array}$ \\
\hline Fuel consumption per vehicle (gallons) & 754.592 & 369.114 & $1,834.413$ & 173.015 \\
\hline Miles traveled per vehicle & 12,323 & 1,968 & 32,340 & 2,821 \\
\hline
\end{tabular}

Source: Office of Highway Policy Information, 2014, retrieved from www.fhwa.dot.gov/policyinformation/ statistics.cfm, 2016.

\section{Independent variables}

In order to accurately test the relationship between AFVs, fuel consumption, and travel per vehicle I employed a number of independent variables to control for the potential influence of related time-variant factors (Table 2). I controlled for the effect of change in the ratio of licensed drivers to vehicles, which helps to control for the impact of changes in the driving pool from year to year. The data for this variable also come from OHPI. I also controlled for the effect of changes in gross domestic product (GDP) per capita in 2009 constant US dollars to account for the 
influence of changes in the economy. The data for GDP per capita were obtained from the Bureau of Economic Analysis. ${ }^{3}$ While it seems appropriate in an analysis like this to control for year-to-year fluctuations in fuel prices, data at the state level were unfortunately not available. To address the potential influence of fuel prices, I controlled for the impact of tax rates on gasoline, which, coupled with my time dummies that controlled for general period fluctuation in my dependent variables, captured the effect of changes such as price over time. I also controlled for miles traveled per vehicle to assess how changes in the amount of travel by individuals over time affects gasoline consumption. Population data were obtained from the United States Census Bureau. ${ }^{4}$ The main independent variable is percent AFVs (Tables 3 and 4), which accounts for the percentage of civilian vehicles that do not use gasoline out of the entire civilian vehicle fleet. Data on AFVs were obtained from the Energy Information Administration 5 and include the following fuel sources: ethanol (85 per cent or higher) (E85), compressed natural gas, electricity, hydrogen, liquefied natural gas, and liquefied petroleum, measured in gasoline-equivalent gallons. The Energy Information Administration's estimates on AFVs do not include gasoline or diesel-electric hybrids because the primary fuel sources for those vehicles are traditional fuels.

Table 2. Summary statistics of independent variables (unlogged)

\begin{tabular}{|l|c|c|c|c|}
\hline Variable & Mean & Minimum & Maximum & $\begin{array}{c}\text { Standard } \\
\text { deviation }\end{array}$ \\
\hline Percent alternatively fueled vehicles (E85) & .071 & .0004 & .393 & .070 \\
\hline Percent alternatively fueled vehicles (no E85) & .019 & .0002 & .393 & .028 \\
\hline GDP per capita (US dollars) & 46,477 & 30,211 & 74,273 & 8,549 \\
\hline Ratio of drivers to vehicles & .744 & .369 & 1.137 & .102 \\
\hline Gasoline tax rate (US cents) & 21.256 & 7.5 & 37.5 & 5.465 \\
\hline
\end{tabular}

Sources: Bureau of Economic Analysis, www.bea.gov; Office of Highway Policy Information, 2014, retrieved from www.fhwa.dot.gov/policyinformation/statistics.cfm, 2016.

There are several inconsistencies in the data for AFVs that I addressed by assessing the robustness of my findings. First, data on the number of vehicles using E85 were unavailable before 2010. Due to the substantial number of AFVs that rely on E85, I found it appropriate to analyze the extent to which this data inconsistency potentially biases my results. In models not shown here (but can be obtained upon request), I assessed the effect of percent changes in AFVs without addressing this inconsistency in the data-in these models the effect of AFVs is the same (coefficients were still significant at $p<.01$ and the direction of the coefficients were the same). Additionally, in models not shown here I assessed the effect of AFVs from 2003

3 Bureau of Economic Analysis, www.bea.gov, retrieved April 2014.

4 United States Census Bureau, 2012 National population projections, retrieved from www.census.gov.

5 Energy Information Administration, www.eia.gov, retrieved April 2014. 
to 2010 and from 2010 to 2014 separately. In each of these models, the effect of AFVs is the same. The models shown in this paper exclude E85 fuel entirely due to inconsistency in the data. It is also important to note that, according to the Energy Information Administration, due to the limited availability and economic viability of E85 fuel, the vast majority of AFVs owned by individuals use gasoline and diesel.

\section{Results}

The PCSE models used to test my hypotheses control for omitted factors that vary across states but are temporally invariant, such as the effects of the historical legacy preceding the periods examined here (e.g., the era during which a state introduced AFVs). The models, therefore, control for characteristics unique to each state. Additionally, the models control (via the time dummies) for cross-sectional invariant factors that change over time, such as fluctuations in international energy prices. Thus, results specifically show the effects of within-unit change in the independent variables on the dependent variables.

Table 3 presents the PCSE model that regresses total fuel consumption on percent AFVs, miles traveled per vehicle, GDP per capita, the ratio of licensed drivers to vehicles, and tax on gasoline. These models test my hypothesis that increases in the percent of AFVs will increase total fuel consumption against the null hypothesis, which is that there is no relationship between AFVs and total fuel consumption for vehicles, and the alternative hypothesis, which supports the conventional view that AFVs displace traditional fuel. Model A in Table 3 omits miles traveled per vehicle to assess the combination of both the potential direct effect of percent AFVs and an indirect effect of AFVs via its influence on miles traveled. Here I find the variable percent AFVs is associated positively with fuel consumption per vehicle $(p<.001$, two-tailed test). This indicates that the rise in percent of AFVs proportionally increases the amount of fuel consumption per vehicle. GDP per capita is also positive and significant in Model A ( $p<.001$, two-tailed test), which demonstrates that growth in the economy through time increases total fuel consumption per vehicle. Additionally, a one-unit increase in the ratio of licensed drivers to vehicles is positive and significantly correlated with fuel consumption per vehicle $(p<.001)$, which means that as the ratio of drivers to vehicles rises, there is an increase in the average amount of fuel consumed per vehicle. Thus Model A demonstrates that rises in the number of AFVs in the vehicle fleet over time within states increases total fuel consumption per vehicle, while holding constant changes in size of the economy, percentage of the population that has a driver's license, gasoline tax rate, and the general period fluctuation in total fuel consumption (Table 3). This finding supports hypothesis 2 , that AFVs are adding to the consumption rates of total fuel consumption. 
Model B (Table 3) is meant to further test my hypothesis, by controlling for miles traveled per vehicle in addition to the independent variables used in Model A. Here I find that percent AFVs is still significantly correlated with fuel consumption per vehicle; however, the effect of a one-unit increase in the percent of AFVs is much smaller. Similar to Model A, GDP per capita and the ratio of licensed drivers to vehicles are also positive and significant in Model B $(p<.001$, two-tailed test). The independent variable miles traveled per vehicle in Model B is positively correlated with total fuel consumption per vehicle ( $p<.001$, two-tailed test). This means that, unsurprisingly, increases in travel per vehicle increase the amount of fuel consumed per vehicle. The change in the overall effect in percent AFVs when adding miles traveled per vehicle as an independent variable in Model B implies that the influence of AFVs on fuel is most likely heavily tied to AFVs' relationship to vehicle travel. The findings in Model B also confirm hypothesis 2.

Table 3. Prais-Winsten regression model with panel-corrected standard errors coefficients predicting gallons of fuel consumption per vehicle

\begin{tabular}{|l|c|c|}
\hline Independent variables (logged) & $\begin{array}{c}\text { Model A coefficients } \\
\text { (standard errors) }\end{array}$ & $\begin{array}{c}\text { Model B coefficients } \\
\text { (standard errors) }\end{array}$ \\
\hline Percent alternatively fueled vehicles & $.032^{\star \star \star}(.008)$ & $.009^{\star \star}(.003)$ \\
\hline Miles traveled per vehicle ('000s of miles) & & $.539^{\star \star \star}(.058)$ \\
\hline GDP per capita in constant 2009 dollars $(\$ ' 000)$ & $.894^{\star \star \star}(.083)$ & $.663^{\star \star \star}(.044)$ \\
\hline Ratio of licensed drivers to vehicles & $.244^{\star \star \star}(.032)$ & $.116^{\star \star \star}(.026)$ \\
\hline Gasoline tax rate (in cents) & $-.028(.033)$ & $-.012(.044)$ \\
\hline$R^{2}$ & .886 & .917 \\
\hline High variance inflation factor & 4.42 & 4.41 \\
\hline$N$ & 600 & 600 \\
\hline
\end{tabular}

${ }^{\star} p<.05$, two-tailed. ${ }^{\star \star} p<.01$, two-tailed. ${ }^{* \star} p<.001$, two-tailed.

Table 4 presents the PCSE coefficients for miles traveled per vehicle and is meant to explore my hypothesis that increasing the proportion of AFVs increases travel per vehicle. Here, percent AFVs is found to be positive and significant $(p<.001$, twotailed test). Specifically, a one-unit increase in the percent of AFVs corresponds with a proportional increase in miles traveled per vehicle. This confirms hypothesis 4 by demonstrating that AFVs are increasing the average travel per vehicle in the United States. Furthermore, my analysis shows that increases in economic development lead to significant increases in miles traveled per vehicle. Rises in the gasoline tax rate as well as the ratio of licensed drivers to vehicles are also correlated with increases in the number of miles traveled per vehicle in the United States (Table 4). 
Table 4. Prais-Winsten regression model with panel-corrected standard errors coefficients predicting miles traveled per vehicle

\begin{tabular}{|l|c|}
\hline Independent variables (logged) & Coefficients (standard errors) \\
\hline Percent alternatively fueled vehicles & $.044^{\star \star \star}(.008)$ \\
\hline GDP per capita in constant 2009 dollars (\$'000s) & $.432^{\star \star \star}(.077)$ \\
\hline Gasoline tax rate (US cents) & $.092^{\star \star}(.031)$ \\
\hline Ratio of drivers to vehicles & $.234^{\star \star *}(.024)$ \\
\hline$R^{2}$ & .857 \\
\hline High variance inflation factor & 4.34 \\
\hline$N$ & 600 \\
\hline
\end{tabular}

${ }^{\star} p<.05$, two-tailed. ${ }^{*} p<.01$, two-tailed. ${ }^{* \star} p<.001$, two-tailed.

\section{Discussion and conclusion}

My analysis finds that AFVs are associated with increases in total fuel consumption per vehicle, as well as rises in travel rates per vehicle. These findings suggest that AFVs are expanding vehicle use in the United States rather than shifting fuel consumption away from traditional sources (e.g., gasoline and diesel). Consequently, this means that AFVs may be increasing environmental impacts produced from the vehicle industry. One lesson to be learned from this analysis is that the assumption that AFVs work to reduce the use of fossil fuels at this point is not true. While this is not to say there are no environmental merits to AFVs, it does demonstrate that current social and economic barriers prevent the widespread use of AFVs.

One interpretation of these findings is that the social and economic barriers presented by other scholars regarding further integration of AFVs into the vehicle fleet (see, e.g., Tran et al., 2013; Zhang et al., 2011) also work to produce a positive relationship between AFVs and travel. That is, unless there is greater support for alternative fuel stations, reduced price premiums for AFVs, and greater consumer concern for environmental impacts, AFVs will continually work to increase travel and consequently the environmental degradation produced by the vehicle industry.

These trends can also be understood as a facet of the treadmill of production, which suggests that the expansion of vehicle use through the production of AFVs is a result of increased supply for natural resources in the vehicle industry, enhancing demand. That is, as a niche market, AFVs are not used to replace traditional vehicles, but instead enhance vehicle use. Using this interpretation, one could imagine many scenarios in which AFVs expand total vehicle use. For example, individuals who traditionally refrain from using personal vehicles for travel due to their negative environmental outcomes may use AFVs due to their perceived environmental merits. Additionally, people who use traditional vehicles may use AFVs to expand their 
travel via personal vehicles. In these scenarios AFVs adhere to York's (2004) notion of the "treadmill of diversifying production," where AFVs function as a reaction to the environmental impacts of traditional fuel consumption, and not a counterforce.

Similar to York (2012) and McGee (2015), my findings demonstrate a paradox in ecologically sustainable production. As York and McGee find with energy and agriculture respectively, alternative goods or resources do not have their assumed relationship with environmental degradation or traditional processes. Similarly, my findings suggest that AFVs do not have their expected relationship to traditional vehicles. While this relationship may change over time, it is worth noting that if the present barriers that prevent further integration of AFVs into the vehicle fleet persist, then the expansion of AFVs may continue to increase total vehicle use in the United States.

AFVs may also increase fuel consumption for vehicles similarly to the rebound effect (see Greening et al., 2000; Small \& Van Dender, 2005, 2007; Sorrell, 2007), where consumption rates for gasoline grow due to lower cost from increased fuel efficiency. It is likely that rises in the number of AFVs is correlated with increases in fuel-efficient vehicles, such as electric-hybrid, which could intensify consumption of gasoline by reducing its cost. Furthermore, it is argued that the rebound effect is a result of increased travel: the findings here demonstrate a strong correlation between travel and AFVs, suggesting that increased travel perpetuates both phenomena.

In conclusion, these results coupled with the findings of Moriarty (1994), Segal (1995), Lapin et al. (2002), Ogden et al. (2004), Hill et al. (2006), and Lapola et al. (2010) suggest that the environmental impacts associated with AFV production are, at this point in time, additions to the vehicle industry's hazardous environmental output. This finding warrants further investigation into other paradoxes in environmentally sustainable production. Additionally, future research and policy should emphasize the types of barriers producing these outcomes and their potential remedies.

\section{References}

Baran, P. A., \& Sweezy, P. M. (1966). Monopoly capital: An essay on the American economic and social order. New York, NY: Monthly Review Press.

Beck, N., \& Katz, J. N. (1995). What to do (and not to do) with time-series cross-section data. American Political Science Review, 89(3), 634-647. doi.org/ $10.2307 / 2082979$ 
Besek, J. F., \& McGee, J. A. (2014). Introducing the ecological explosion: A crossnational analysis of invasive species and economic development. International Journal of Sociology, 44(1), 75-93. doi.org/10.2753/IJS0020-7659440105

Clark, B., \& Foster, J. B. (2001). William Stanley Jevons and the coal question: An introduction to Jevons's "Of the economy of fuel." Organization \& Environment, 14(1), 93-98. doi.org/10.1177/1086026601141005

Clausen, R., \& York, R. (2008). Global biodiversity decline of marine and freshwater fish: A cross-national analysis of economic, demographic, and ecological influences. Social Science Research, 37(4), 1310-1320. doi.org/10.1016/j. ssresearch.2007.10.002

Clement, M. T., \& Schultz, J. (2011). Political economy, ecological modernization, and energy use: A panel analysis of state-level energy use in the United States, 1960-1990. Sociological Forum, 26(3), 581-600. doi.org/10.1111/j.15737861.2011.01263.x

Egbue, O., \& Long, S. (2012). Barriers to widespread adoption of electric vehicles: An analysis of consumer attitudes and perceptions. Energy Policy, 48(3), 717-729. doi.org/10.1016/j.enpol.2012.06.009

Fisher, D. R., \& Freudenburg, W. R. (2001). Ecological modernization and its critics: Assessing the past and looking toward the future. Society \& Natural Resources, 14(8), 701-709. doi.org/10.1080/08941920152524891

Foster, J. B. (1999). Marx's theory of metabolic rift: Classical foundations for environmental sociology. American Journal of Sociology, 105(2), 366-405. doi.org/10.1086/210315

Foster, J. B. (2000). Marx's ecology: Materialism and nature. New York, NY: Monthly Review Press.

Gould, K. A., Pellow, D. N., \& Schnaiberg, A. (2004). Interrogating the treadmill of production: Everything you wanted to know about the treadmill but were afraid to ask. Organization \& Environment, 17(3), 296-316. doi. org $/ 10.1177 / 1086026604268747$

Gould, K. A., Pellow, D. N., \& Schnaiberg, A. (2008). The treadmill of production: Injustice and unsustainability in the global economy. Boulder, CO: Paradigm Publishers.

Greening, L. A., Greene, D. L., \& Difiglio, C. (2000). Energy efficiency and consumption-The rebound effect-A survey. Energy Policy, 28(6-7), 389-401. doi.org/10.1016/S0301-4215(00)00021-5 
Hill, J., Nelson, E., Tilman, D., Polasky, S., \& Tiffany, D. (2006). Environmental, economic, and energetic costs and benefits of biodiesel and ethanol biofuels. Proceedings of the National Academy of Sciences of the United States of America, 103(30), 11206-11210. doi.org/10.1073/pnas.0604600103

Jorgenson, A. K., \& Clark, B. (2012). Are the economy and the environment decoupling? A comparative international study, 1960-2005. American Journal of Sociology, 118(1), 1-44. doi.org/10.1086/665990

Lapin, C. A., Gautam, M., Zielinska, B., Wagner, V. O., \& McClellan, R. O. (2002). Mutagenicity of emissions from a natural gas fueled truck. Mutation Research: Genetic Toxicology and Environmental Mutagenesis, 519(1-2), 205-209. doi.org/10.1016/S1383-5718(02)00140-7

Lapola, D. M., Schaldach, R., Alcamo, J., Bondeau, A., Koch, J., Koelking, C., \& Priess, J. A. (2010). Indirect land-use changes can overcome carbon savings from biofuels in Brazil. Proceedings of the National Academy of Sciences of the United States of America, 107(8), 3388-3393. doi.org/10.1073/pnas.0907318107

McGee, J. A. (2015). Does certified organic farming reduce greenhouse gas emissions from agricultural production? Agriculture and Human Values, 32(2), 255-263. doi.org/10.1007/s10460-014-9543-1

Mol, A. P. J., Sonnenfeld, D. A., \& Spaargaren, G. (Eds.). (2009). The ecological modernisation reader: Environmental reform in theory and practice. New York, NY: Routledge.

Mol, A. P. J., Spaargaren, G., \& Sonnenfeld, D. A. (2014). Ecological modernization theory: Taking stock, moving forward. In S. Lockie, D. A. Sonnenfeld, \& D. R. Fisher (Eds.), Handbook of social and environmental change (pp. 15-30). London: Routledge.

Moriarty, P. (1994). Can alternative car fuels reduce greenhouse gas emissions? International Journal of Vehicle Design, 15(1-2), 1-7.

National Renewable Energy Laboratory. (2013). Alternative fuel infrastructure expansion: Costs, resources, production capacity, and retail availability for lowcarbon scenarios. Transportation energy futures series. Washington, DC: Office of Energy Efficiency \& Renewable Energy.

Ogden, J. M., Williams, R. H., \& Larson, E. D. (2004). Societal lifecycle costs of cars with alternative fuels/engines. Energy Policy, 32(1), 7-27. doi.org/10.1016/ S0301-4215(02)00246-X

OHPI (Office of Highway Policy Information). (2015). Guide to reporting highway statistics. 
Sarkis, J., \& Cordeiro, J. J. (2012). Ecological modernization in the electrical utility industry: An application of a bads-goods DEA model of ecological and technical efficiency. European Journal of Operational Research, 219(2), 386-395. doi.org/10.1016/j.ejor.2011.09.033

Schnaiberg, A. (1980). The environment: From surplus to scarcity. New York, NY: Oxford University Press.

Schnaiberg, A., \& Gould, K. A. (1994). Environment and society: The enduring conflict. New York: St Martin's Press.

Schnaiberg, A., Pellow, D. N., \& Weinberg, A. (2002). The treadmill of production and the environmental state. In A. P. J. Mol \& F. H. Buttel (Eds.), The environmental state under pressure (Research in Social Problems and Public Policy, Vol. 10, pp. 15-32). Emerald Group Publishing. doi.org/10.1016/s0196$1152(02) 80004-7$

Segal, R. (1995). Forecasting the market for electric vehicles in California using conjoint analysis. The Energy Journal, 16(3), 89-111. doi.org/10.5547/ ISSN0195-6574-EJ-Vol16-No3-4

Sellen, A. J., \& Harper, R. H. (2003). The myth of the paperless office. Cambridge, MA: MIT Press.

Small, K., \& Van Dender, K. (2005). The effect of improved fuel economy on vehicle miles traveled: Estimating the rebound effect using U.S. state data, 1966-2001. Berkeley, CA: University of California Energy Institute.

Small, K., \& Van Dender, K. (2007). Fuel efficiency and motor vehicle travel: The declining rebound effect. The Energy Journal, 28(1), 25-51. doi.org/10.5547/ ISSN0195-6574-EJ-Vol28-No1-2

Sorrell, S. (2007). The rebound effect: An assessment of the evidence for economy-wide energy savings from improved energy efficiency. UK Energy Research Centre.

Tran, M., Banister, D., Bishop, J. D. K., \& McCulloch, M. D. (2013). Simulating early adoption of alternative fuel vehicles for sustainability. Technological Forecasting and Social Change, 80(5), 865-875. doi.org/10.1016/j.techfore.2012.09.009

UNEP (United Nations Environment Programme). (2011). Towards a green economy: Pathways to sustainable development and poverty eradication. Retrieved from www.unep.org/greeneconomy/resources/green-economy-report

Wattanapinyo, A., \& Mol, A. P. J. (2013). Ecological modernization and environmental policy reform in Thailand: The case of food processing SMEs. Sustainable Development, 21(5), 309-323. doi.org/10.1002/sd.506 
York, R. (2004). The treadmill of (diversifying) production. Organization \& Environment, 17(3), 355-362. doi.org/10.1177/1086026604268023

York, R. (2006). Ecological paradoxes: William Stanley Jevons and the paperless office. Human Ecology Review, 13(2), 143-147.

York, R. (2012). Do alternative energy sources displace fossil fuels? Nature Climate Change, 2(6), 441-443. doi.org/10.1038/nclimate1451

York, R., \& Rosa, E. A. (2003). Key challenges to ecological modernization theory: Institutional efficacy, case study evidence, units of analysis, and the pace of ecoefficiency. Organization \& Environment, 16(3), 273-288. doi.org/10.1177/ 1086026603256299

York, R., Rosa, E. A., \& Dietz, T. (2003). Footprints on the earth: The environmental consequences of modernity. American Sociological Review, 68(2), 279-300. doi.org/10.2307/1519769

Zhang, T., Gensler, S., \& Garcia, R. (2011). A study of the diffusion of alternative fuel vehicles: An agent-based modeling approach. Journal of Product Innovation Management, 28(2), 152-168. doi.org/10.1111/j.1540-5885.2011.00789.x

Zhu, Q., Sarkis, J., \& Lai, K.-H. (2012). Green supply chain management innovation diffusion and its relationship to organizational improvement: An ecological modernization perspective. Journal of Engineering and Technology Management, 29(1), 168-185. doi.org/10.1016/j.jengtecman.2011.09.012 
This text is taken from Human Ecology Review, Volume 23, Number 1, 2017, published 2017 by ANU Press, The Australian National University, Canberra, Australia.

dx.doi.org/10.22459/HER.23.01.2017.05 